\title{
Measuring Seasonality of Tourism Demand in Petra, Jordan (2006- 2017)
}

\author{
Nidal Alzboun ${ }^{1}$ \\ ${ }^{1}$ Department of Geography, School of Arts, The University of Jordan, Amman, Jordan \\ Correspondence: Nidal Alzboun, Department of Geography, School of Arts, The University of Jordan, Amman, \\ Jordan. E-mail: n.alzboun@ju.edu.jo
}

Received: July 20, 2018

doi:10.5539/mas.v12n9p131
Accepted: August 4, $2018 \quad$ Online Published: August 21, 2018

URL: https://doi.org/10.5539/mas.v12n9p131

\begin{abstract}
Petra is a mature tourism destination in the south of Jordan with a degree of seasonality over the last 10 years. Despite the recognized importance of Petra for the tourism industry in Jordan, there has been a lack of studies that discuss seasonal demand variations and its impacts on other related industries in the region. Yet, this study aims at analyzing patterns and effects of seasonality of tourism demand in Petra for the period 2006-2017. The required data was obtained from Ministry of Tourism and Antiquities (MoTA). Four methods were used to measure tourism seasonality in Petra. These are: Seasonality indicator; Seasonality ratio; Gini coefficient; and Seasonality index. The results of the study showed a modest level of tourism seasonality in the study area. Among methods, Seasonality index appeared to be the appropriate and simple way to calculate seasonality patterns at tourism destinations. The results showed that there are two peaks of seasonality in tourism demand of Petra. The first and the highest one was in April and the second took place in the months of October and November. In addition, seven months represented the low season of tourism demand in Petra. These are December, January and February as well as June, July, August and September. The tourism seasonality in Petra based on that is mainly due to the weather in these months which represent the coldest and warmest months in the year respectively.
\end{abstract}

Keywords: tourism seasonality, Petra, seasonal index, Gini coefficient, seasonality patterns

\section{Introduction and Research Background}

The phenomenon of tourism seasonality is one of the major challenges that most tourism destinations experience around the world. Accordingly, seasonality issue has gained a considerable attention of not only academics, but also professionals and decision makers involved in the tourism sector. The first definition of tourism seasonality was presented in 1975 by Baron in his comprehensive work considering it as the yearly effects caused by changing in tourists' numbers during the year. In 1989, Allcock defined "seasonality" in the context of tourism as concentration of tourism flows in a certain period of time in a destination country. On the other hand, Hylleberg (1992) states that "seasonality is the systematic, although not necessarily regular, intra-year movement caused by changes in the weather, the calendar, and timing of decisions, directly or indirectly through the production and consumption decisions made by the agents of the economy". In the mid of 1990s, Butler stated that tourism seasonality is a "temporal imbalance in the number of visitors, traffic on highways, employment and admission to attractions" (Butler (1994). Most recently, Chung (2009) considered seasonality as a temporary movement of people around the world. All of these definitions agree upon the fact that tourism seasonality is a temporal variation of tourists' numbers affecting both tourism demand and tourism supply sides.

Most studies categorized the main factors causing seasonality in tourism demand in two categories: natural and institutional. Natural factors are represented by climate elements including; temperature, rainfall, snowfall, sunlight, and daylight (BarOn, 1975; Butler, 1994; Butler and Mao, 1997; Commons and Page, 2001; Goulding et al, 2004; Kulendran \& Dwyer, 2010; Soboll and Dingeldey, 2012; Zhang and Kulendran. 2017; Ridderstaat, Oduber, Croes, Nijkamp, and Martens., 2014; Fang, and Yin, 2015). To get better understanding of natural causes' influencing on tourism seasonality, we have to cope with tourism as a system, that unattractive factors in generating regions (demand side) could be attractive factors in receiving areas (supply side) (Lee et al, 2008). In addition, institutional or cultural factors of seasonality include; holidays (school and religious) (Goulding et al, 2004); travel habits and motivations (Commons and Page, 2001; Goulding et al, 2004; Jang, 2004); and timing of events (Jang, 2004). 
As tourism demand varies spatially, it also varies temporally leading to some negative influences on economic, social, and environmental aspects influences on tourism destinations, and local communities (Derrouiche and Mebirouk, 2015). A range of studies have highlighted negative influences of peak seasons including increase in prices (Commons and Page, 2001; Goh, 2012; Hinch and Jackson, 2000); over utilization of resources (Jang, 2004); pressure on infrastructure (Commons and Page, 2001); overcrowding leads to environmental problems such as pollution, sewage disposable problem and noise (Butler, 2001), risk of terrorism (Butler, 2001; Jang, 2004), and reduced quality of service which affects tourists' satisfaction (Baum and Morrison, 2004). As well as, shortages of seasonal workers, force tourism properties to recruit workers with low skills and experience, uncommitted workers and sometimes beyond local area (Commons and Page, 2001). In such conditions, businesses may suffer a decline in their profit that would not be compensated in the low or off-season (Parrilla et al., 2007). Whereas, the positive influences of high seasons comprise providing more jobs and acceptable salaries for both locals and other labors. In addition, peak seasons increase the share of tourism sector in the country's GDP, which will be reflected on the quality of life of locals and quality of infrastructure and provided services. Furthermore, it also contributes in creating more successful economic activities for both formal and informal sectors.

Second, off-seasons, in general, have more negative effects on tourism destinations than the high seasons. However, the negative effects of seasonality in the context of tourism, include low annual returns on capital (Butler, 1994; Cooper et al., 2005; Pegg et al., 2012), effects on employment (Pegg, et al., 2012; Krakover, 2000; Getz and Nilsson, 2004; Butler, 1994), and environment (Butler, 1994). Tourism destinations with high variation of demand are described as unstable labor markets, that tourism employers couldn't afford workers' salaries during off- peak seasons, at the same time, the employees are looking for stable jobs (Chung, 2009). With regard to investments, the literature indicated that accommodations and food services are the most affected businesses during off-peak seasons (Soesilo \& Mings, 1986). Furthermore, destination image and destination choice will also be negatively affected by low tourism demand (Guh, 2012). Off-peak seasons, however, have some positive impacts which can be represented by providing a part-time work for locals and others (Krakover, 2000). It also gives required time for environmental resources recovery and properties renovation (Butler, 1994; Witt and Moutinho, 1995).

According to the literature, several statistic measures have been employed to measure and analyze seasonality patterns (Baron, 1975; Coshall. et al., 2015; Chen and Pearce, 2012; Duro, 2016; Fernandez-Morales. et al., 2016; Jang, 2004; Karamustafa and Ulama, 2010; Koenig \& Bischoff, 2005; Lundtorp. 2001; Nadal et al., 2004; Rosselló and Sansó, 2017; Wall 7 Yan, 2003). These measures include "seasonality range" (difference between highest and lowest monthly indices), "seasonality ratio" (the largest seasonal value divided by the average), "The seasonality indicator" (the average divided by the largest value), "The Gini coefficient", (The maximal annual utilization factor constrained by seasonality), and seasonal index which shows seasonal variations through comparing increases and decreases of demand to the average during the season (Karamustafa and Ulama, 2010).

A good Understanding of seasonality patterns which impact tourism consumption and production is crucial for efficient operation of tourism enterprises and regions (Chan and Lim, 2011; Cuccia and Rizzo, 2011; Koc and Altinay, 2007). Wall and Mathieson (2006, 57) stated that tourist destinations experience an annual cycle with two main seasons namely a peak season and an off-season separated by two shoulder seasons. Tourism destinations that are rely primarily on weather as the main attraction follow a one peak pattern. For example, the summer months are the peak season in Mediterranean countries whose tourism demand is primarily driven by warm weather (Karamustafa and Ulama, 2010).

In the context of Jordan, tourism is one of the major pillars in Jordan's economy contributing to $23 \%$ of Jordanian GDP, as well as providing 310 thousand job opportunities (direct and indirect) (WTTC, 2015). The variety of tourism products including its antiquities, religious attractions, as well as natural resources, all of these puts Jordan on the global tourism map. Petra is a main pillar of the tourism industry in the country. It is the great Nabataean capital and commercial centre carved in the red sandstone, locates 260 kilometres southern Amman (Mustafa \& Abu Tayeh, 2011). In 1985, Petra has been listed as a World Heritage Site, and in 2007, it was announced as the second one of new seven wonders. The number of tourists visiting Petra grew up from 359 thousand in 2006 to 620 thousand in 2017 (MoTA, 2017). However, the number of tourists visiting Petra is fluctuating from month to month, and from year to year, which may cause some consequences of tourism supply (services, hotels, restaurants, and jobs...etc).

In spite of the importance of the tourism industry in Jordan in general and Petra in particular, few studies have focused on tourism demand in the country. Rawashdeh (2014) conducted a study to measure tourism seasonality in Jordan using Gini Coefficient. The study results indicated that Jordan has a low level of tourism seasonality due to the variety of generating tourists' destinations. According to Rawashdeh (2014), tourism demand in Jordan has low level of seasonality due to having different tourism destinations that attract all types of tourists. Petra, as an 
archeological site has specific type of tourists. It is assumed that Petra has a high level of seasonality comparing to the average level of seasonality for tourism demand in Jordan. Mediterranean climate of Jordan attracts tourists from hot climates such as Gulf countries and cold ones such as Europeans alike. In 2006, Aljamaliah studied tourism seasonality in Petra employing Gini Coefficient. According to the results, GC was high (0.37) indicating to a high level of seasonality in Petra and peak seasons were spring and fall. Since Aljamaliah research focused on one method to measure tourism seasonality in Petra before 12 years ago, the current study aims to bridge this gab in the literature being the first study to use multiple measurements to determine seasonality patterns in Petra depending on data from 2006 to 2017.

Thus, the aim of this study is to measure tourism seasonality in Petra using different methods (seasonality indicator, seasonality ratio, Gini coefficient, and seasonality index) for the period of 2006-2017, to analyze the patterns of tourism seasonality in Petra. In addition, it seeks to identify the causes and effects of tourism seasonality in Petra. The importance of this study springs from the fact that Petra is a remote destination from Amman (the capital of Jordan) and other large cities in the country, located in the southern east part of the arid land of Jordan. This situation makes tourism the only possible sector to lead development in the region of Petra, as one of the most tourist attraction destination. In addition, determining seasonality patterns (the peak-, shoulder- and off-peak seasons) by months for any destination is vital issue in planning process for sustainability (Karamustafa and Ulama, 2010).

\section{Data sources and Methods}

The body of a manuscript opens with an introduction that presents the specific problem under study and describes the research strategy. Because the introduction is clearly identified by its position in the manuscript, it does not carry a heading labeling it the introduction. Before writing the introduction, consider the following questions (Beck and Sales, 2001, p. 100):

The required data for the study period (2006-2017) was obtained from The Ministry of Tourism and Antiquities (MoTA) statistics including the number of tourists' arrivals to Petra and their nationalities, hotels' occupancy rate, number of employees, and the number of hotels and their classification. The researcher selected this period because of the availability of the required data.

To achieve the study purposes, the common and widely used methods to measure seasonality were employed to measure tourism seasonality in Petra. These are: Seasonality indicator; Seasonality ratio; Gini coefficient; and Seasonality index. They were calculated as explained in more details in Karamustafa \& Ulama (2010); Chung (2009); Weidner (2006); Nadal et al., (2004); and Koenig and Bischoff (2005). To summarize:

- The Seasonality Ratio: is "the largest number of visitors (in monthly basis) in the year (for Petra) divided by the average number of visitors for the same year". Its values rage from 1 to 12 . This means, when SR equals 1, the number of visitors is constant for every month (no seasonality), while 12 indicates to the highest level of seasonality meaning that visitors are concentrated on one month (Karamustafa and Ulama, 2010).

- The Seasonality Indicator: is "the average number of visitors (for Petra) in the year divided by the largest number of visitors for the same year. Which means it is "the inverse value of the seasonality ratio". Seasonality indicator value ranges from $1 / 12$ to 1 . If the number of visitors arriving is the same every month, the seasonality indicator equals 1 . If the number of visitors arriving concentrates on one month then the seasonality indicator is $1 / 12$.

- The Gini coefficient:

$$
\mathrm{G}=\frac{2}{n} \sum_{i=1}^{n}\left(x_{i}-y_{i}\right)
$$

Where: $n=$ ratio value (in the case of this study, number of months $=12$ ),

$x_{i}=$ ratio order (i.e. $\left.1 / 12,2 / 12, \ldots \ldots ., 12 / 12\right)$; and,

$y_{i}=$ cumulative actual ratios in the Lorenz curve.

When Gini coefficient $=0$, this means that the number of visitors does not differ from month to month during the year. If $\mathrm{G}=1$, this indicates that there is a complete inequality of monthly visitors' concentrations (Kulendran \& Wong, 2005).

- The seasonality index: is calculated through the following steps:

- Calculating the moving average of tourist arrival (in Petra) for the 12 months of the first year of the study 
period (2006 for this study) and the same calculation continues for next 12 months of the second year until the last 12 months of the last year of the study period (2017).

- Calculating the central moving average for every two months (Jan. and Feb., and then Feb. and March ...etc) for the whole period of the study.

- In order to calculate the seasonality index, the number of tourists' arrivals (in each month for all years) is divided by the central moving average of that month.

1- Calculating the total number of the yield number in step 3 for each month for all years (i.e. the total number of the yield number in step 3 for January for all years of the study period (2006-2017) and run the same calculation for all other months).

2- Dividing the yield number in step 4 by the number of years ( 12 for this study) to calculate the average.

3- Calculating the adjusted average of all months to make sure that they equal 12 together.

4- And finally, Multiplying the adjusted average by 100 to find the Seasonal Index.

Karamustafa and Ulama (2010) made a comparison between the four mentioned seasonality methods in terms of their strengths and weaknesses. They stated that Seasonality ratio measures the seasonal intensity and Seasonality indicator points to the seasonal capacity of the accommodation establishments. On the other hand, both methods do not take account of the skewness of distribution and influenced by extreme values and they only focus on oneyear data. Whereas, Gini coefficient evaluates the whole year and can make comparisons among the years, which makes it a practical measure in various comparisons for tourists' number for different years and based on their nationalities, which can help managers to apply appropriate marketing strategies on seasonality for various markets. Fernandez-Morales and Mayorga-Toledano, (2008) indicated that Gini coefficient shows greater stability than previous methods because it is less influenced by extreme values and more sensitive to variations outside peak seasons. The short coming of this method is that it makes calculations and comparisons depending on a selected year only, where it becomes insufficient in determining the monthly distribution of tourist arrivals since it takes into account only seasonal fluctuations. Finally, Seasonality index constructs a base for the demand forecast since it takes into account the previous several years, which makes it come over the weaknesses of the three previous methods. Furthermore, Seasonal Index calculation is based on moving averages, which takes smooth fluctuations other than seasonality into consideration. However, it cannot be applicable to new destinations since it requires previous data and requires a large amount of data (Karamustafa and Ulama, 2010), which makes it a suitable method for Petra, as a mature tourism destination with a considerable record of data.

\section{Results and discussion:}

\subsection{Seasonality Patterns in Petra}

According to MoTA, the number of Petra's visitors increased from 359 thousand in 2006 to 976 in 2010 which represents the highest number of visitors in Petra during the study period. However, the number of visitors started to decrease in 2011 and the following years due to the effects of the so-called "Arab Spring". Accordingly, the number of tourists fluctuated from year to year reaching to 620 thousand in 2017 (table 1). Furthermore, there is a temporal variation in visitors' numbers from month to month every year during the study period as shown in Table 1 , reflecting a variation in tourism demand in Petra.

Table 1. Number of visitors to Petra during 2006-2017

\begin{tabular}{cccccccccccccccc}
\hline $\begin{array}{c}\text { Years/ } \\
\text { Months }\end{array}$ & $\mathbf{2 0 0 6}$ & $\mathbf{2 0 0 7}$ & $\mathbf{2 0 0 8}$ & $\mathbf{2 0 0 9}$ & $\mathbf{2 0 1 0}$ & $\mathbf{2 0 1 1}$ & $\mathbf{2 0 1 2}$ & $\mathbf{2 0 1 3}$ & $\mathbf{2 0 1 4}$ & $\mathbf{2 0 1 5}$ & $\mathbf{2 0 1 6}$ & $\mathbf{2 0 1 7}$ \\
\hline Jan & 24843 & 25804 & 47444 & 40322 & 57368 & 66419 & 41277 & 42785 & 39059 & 24736 & 16609 & 30658 \\
Feb & 22568 & 28809 & 51568 & 36057 & 59258 & 44326 & 39745 & 45531 & 40902 & 23337 & 24349 & 31742 \\
Mar & 42617 & 46051 & 82488 & 70390 & 103918 & 69660 & 59460 & 73674 & 64064 & 39805 & 46500 & 56899 \\
Apr & 68613 & 80978 & 96136 & 102489 & 126970 & 90376 & 87714 & 85270 & 101039 & 60282 & 57432 & 87513 \\
May & 35705 & 41626 & 82321 & 68977 & 98201 & 47498 & 56858 & 58934 & 65975 & 45314 & 40071 & 57056 \\
Jun & 21027 & 29131 & 49651 & 41346 & 48664 & 32366 & 40197 & 35687 & 42686 & 22946 & 19569 & 33783 \\
Jul & 21374 & 36779 & 45416 & 45680 & 56355 & 39525 & 36252 & 28537 & 27910 & 24738 & 33751 & 32498 \\
Aug & 22713 & 64647 & 55577 & 49988 & 51497 & 24972 & 38034 & 42598 & 36670 & 25430 & 30886 & 34928 \\
Sep & 15845 & 35869 & 55450 & 60622 & 74551 & 44487 & 43634 & 36233 & 36079 & 26601 & 47546 & 52573 \\
Oct & 26594 & 70844 & 99616 & 105866 & 124466 & 57229 & 78249 & 63176 & 60995 & 49607 & 51574 & 74055 \\
Nov & 32142 & 69914 & 89474 & 86933 & 106943 & 70505 & 66483 & 58439 & 49185 & 36034 & 55933 & 75383 \\
\hline
\end{tabular}




\begin{tabular}{ccccccccccccc}
\hline Dec & 25325 & 50897 & 58126 & 58268 & 68094 & 42501 & 48243 & 38180 & 32038 & 29332 & 39934 & 53279 \\
Total & $\mathbf{3 5 9 3 6 6}$ & $\mathbf{5 8 1 3 4 9}$ & $\mathbf{8 1 3 2 6 7}$ & $\mathbf{7 6 6 9 3 8}$ & $\mathbf{9 7 6 2 8 5}$ & $\mathbf{6 2 9 8 6 4}$ & $\mathbf{6 3 6 1 4 6}$ & $\mathbf{6 0 9 0 4 4}$ & $\mathbf{5 9 6} \mathbf{6 0 2}$ & $\mathbf{4 0 8} \mathbf{1 6 7}$ & $\mathbf{4 6 4 1 5 4}$ & $\mathbf{6 2 0 3 6 7}$ \\
\hline
\end{tabular}

Source: MoTA 2006-2017.

Based on the available data of visitors to Petra shown in Table 1, tourism seasonality was measured by the four above mentioned methods as follows:

First, the seasonality ratio was calculated based on the formula explained in the methodology and the results displayed in Table 2. The results showed that seasonality ratio in Petra ranged between 1.42 in 2008 which represent the lowest seasonality during the study period, to 2.29 in 2006 being the highest value of seasonality in Petra. From the results shown in Table 2, it seems that even though there had been seasonality in Petra but it was not significant according to this method (seasonality ratio).

Second, seasonality indictor was also calculated as presented in Table 2 . The values of seasonality indicator in Petra also ranged between 0.44 in 2006 showing the highest seasonality level during the study period, and 0.68 in 2008 representing the lowest level of tourism seasonality in Petra. These results showed that both methods give the same picture about tourism seasonality, which leads to recommend the use of either one of these two methods in measuring seasonality in future research.

Table 2. Seasonality ratio and Seasonality indicator for visitors of Petra (2006-2017).

\begin{tabular}{llllllllllllllll}
\hline $\begin{array}{l}\text { Months/ } \\
\text { Years }\end{array}$ & 1 & 2 & 3 & 4 & 5 & 6 & 7 & 8 & 9 & 10 & 11 & 12 & $\begin{array}{l}\text { Seasonality } \\
\text { Ratio }\end{array}$ & $\begin{array}{l}\text { Seasonality } \\
\text { Indicator }\end{array}$ \\
\hline 2006 & 0.83 & 0.75 & 1.42 & 2.29 & 1.19 & 0.70 & 0.71 & 0.76 & 0.53 & 0.89 & 1.07 & 0.85 & 2.29 & 0.44 \\
2007 & 0.53 & 0.59 & 0.95 & 1.67 & 0.86 & 0.60 & 0.76 & 1.33 & 0.74 & 1.46 & 1.44 & 1.05 & 1.67 & 0.60 \\
2008 & 0.70 & 0.76 & 1.22 & 1.42 & 1.21 & 0.73 & 0.67 & 0.82 & 0.82 & 1.47 & 1.32 & 0.86 & 1.42 & 0.68 \\
2009 & 0.63 & 0.56 & 1.10 & 1.60 & 1.08 & 0.65 & 0.71 & 0.78 & 0.95 & 1.66 & 1.36 & 0.91 & 1.60 & 0.60 \\
2010 & 0.70 & 0.73 & 1.28 & 1.56 & 1.21 & 0.60 & 0.69 & 0.63 & 0.91 & 1.53 & 1.31 & 0.83 & 1.56 & 0.64 \\
2011 & 1.26 & 0.84 & 1.33 & 1.72 & 0.90 & 0.62 & 0.75 & 0.48 & 0.85 & 1.09 & 1.34 & 0.81 & 1.72 & 0.58 \\
2012 & 0.78 & 0.75 & 1.12 & 1.65 & 1.07 & 0.76 & 0.68 & 0.72 & 0.82 & 1.48 & 1.25 & 0.91 & 1.65 & 0.60 \\
2013 & 0.84 & 0.90 & 1.45 & 1.68 & 1.16 & 0.70 & 0.56 & 0.84 & 0.71 & 1.24 & 1.15 & 0.75 & 1.68 & 0.60 \\
2014 & 0.79 & 0.82 & 1.29 & 2.03 & 1.33 & 0.86 & 0.56 & 0.74 & 0.73 & 1.23 & 0.99 & 0.64 & 2.03 & 0.49 \\
2015 & 0.73 & 0.69 & 1.17 & 1.77 & 1.33 & 0.67 & 0.73 & 0.75 & 0.78 & 1.46 & 1.06 & 0.86 & 1.77 & 0.56 \\
2016 & 0.43 & 0.63 & 1.20 & 1.48 & 1.03 & 0.51 & 0.87 & 0.80 & 1.23 & 1.33 & 1.44 & 1.03 & 1.48 & 0.67 \\
2017 & 0.59 & 0.61 & 1.10 & 1.69 & 1.10 & 0.65 & 0.63 & 0.68 & 1.02 & 1.43 & 1.46 & 1.03 & 1.69 & 0.59 \\
\hline
\end{tabular}

Third, Gini coefficient was also calculated for the purpose of measuring seasonality in Petra. The results indicate that calculated values for Gini coefficient during the past thirteen years ranged between 0.16 and 0.22 , which gives a similar result as in both previous methods (seasonality ratio and seasonality indicator). The average value of Gini coefficient for the study period 2006-2017 was 0.19 . The results showed that seasonality in terms of intra-year monthly variations of visitors to Petra was constant during the study period. Based on the results which showed that Gini coefficient values are far below the margin of 0.5 , it is easy to conclude that tourism seasonality level in Petra is modest. Aljamaliah (2006) found that Gini coefficient for tourism seasonality in Petra for the period (19932004 ) is 0.37 which is higher than Gini index value of the current study.

Table 3. Gini coefficient values for visitors of Petra (2006-2017).

\begin{tabular}{llllllllllllll}
\hline Years & $\mathbf{2 0 0 6}$ & $\mathbf{2 0 0 7}$ & $\mathbf{2 0 0 8}$ & $\mathbf{2 0 0 9}$ & $\mathbf{2 0 1 0}$ & $\mathbf{2 0 1 1}$ & $\mathbf{2 0 1 2}$ & $\mathbf{2 0 1 3}$ & $\mathbf{2 0 1 4}$ & $\mathbf{2 0 1 5}$ & $\mathbf{2 0 1 6}$ & $\mathbf{2 0 1 7}$ & Ave. \\
\hline $\begin{array}{l}\text { Gini } \\
\text { Index }\end{array}$ & 0.22 & 0.21 & 0.16 & 0.20 & 0.19 & 0.19 & 0.17 & 0.18 & 0.20 & 0.18 & 0.20 & 0.20 & 0.19 \\
\hline
\end{tabular}

Finally, the seasonal index was also calculated to measure seasonality of tourism demand in Petra according to the above mentioned steps in the methods part of the study. As can be noticed from Figure 1, peak season months in Petra according to seasonality ratio measure are March, April, May, and November, seasonality indices for some months are higher than the average (the peak season months), for some months they are close to the average (the shoulder season months) and for some months are below the average (the off-peak season months). 
According to the calculated seasonal indices of the current study, while April has the highest seasonal index (169.4) for the time-period of 2006 and 2017, June has the lowest value (67.8). From Figure 1, it is also possible to examine the seasonal fluctuations among the months for the same period. In addition, the months of January and February are the first off-peak seasonal months; March and May are the first and second Shoulder-Seasons respectively, April is the first Peak-seasonal month encompassing the highest number of tourists visiting Petra during the years, June-July-August-September are the second Off-peak Seasonal Months; October and November are the second Peak-seasonal months. Based on this description, it can be judged that the tourism in Petra consists of a time period of seven months' low season, a time period of two months' mid-season, and a time period of four months' peak season between 2006 and 2017.

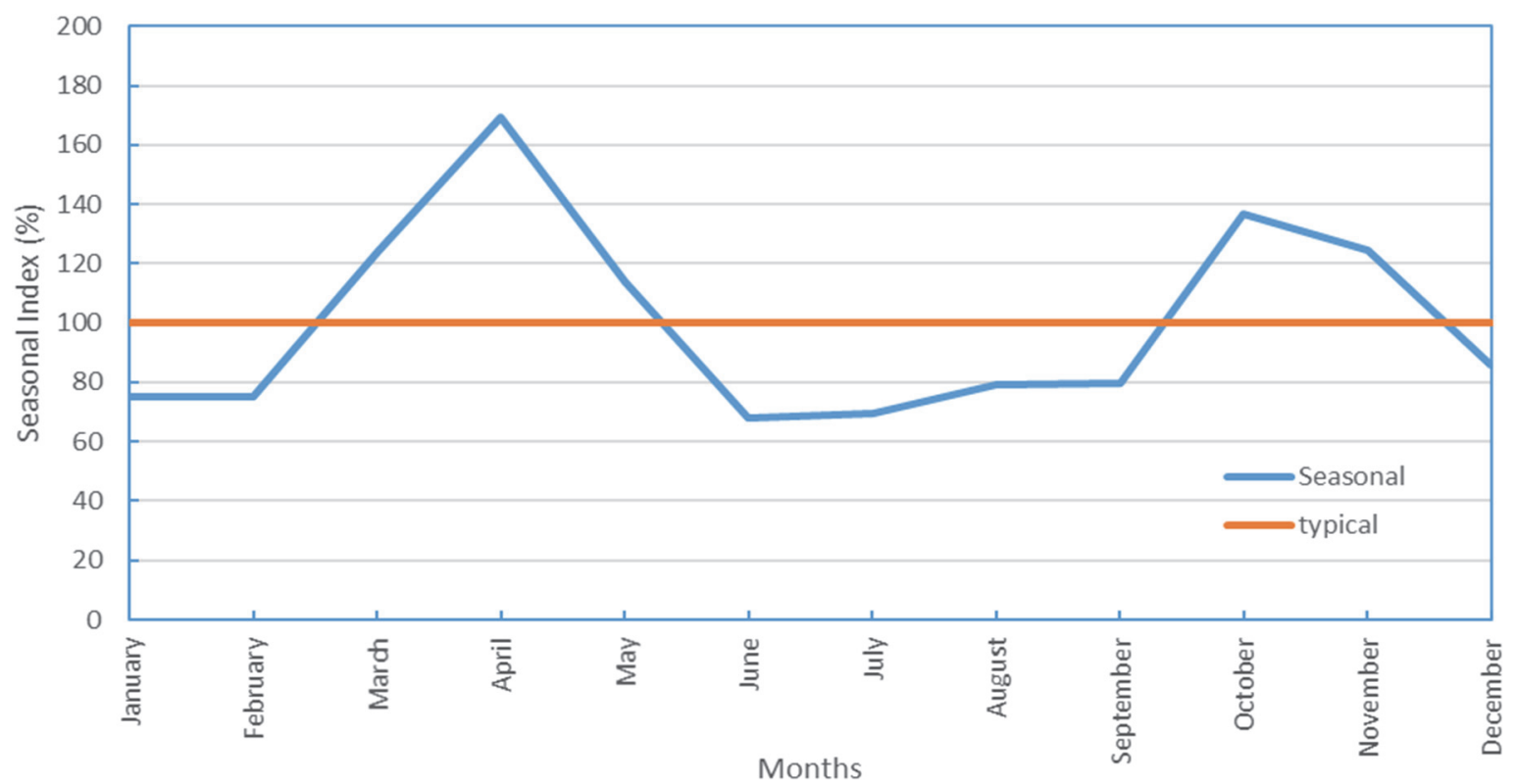

Figure 1. Seasonal indices of visitors to Petra between 2006-2017 by the method of a ratio to moving averages.

On the national scale, as shown in Table 4, there are three peaks of Jordanian visitors to Petra. The first peak season and the highest one takes place in April due to nice weather after a cold winter. The second peak happenes during July and August in accordance with school holiday and expatriates vacation. The third one is smaller than others happenes in October. Based on data presented in Table 4, one may conclude that the peak seasons of international and national visitors to Prtra occurs semultainiously during April and October while Jordanian tourists have another small peak during summer season in July and August. Consequently, this may contribute to alleviate of seasonality effects.

Table 4. Monthly average of Jordanian visitors to Petra during 2006-2017.

Source: MoTA 2006-2017.

\begin{tabular}{cc}
\hline Month & No. of Visitors \\
\hline January & 4700 \\
February & 4200 \\
March & 9500 \\
April & $\mathbf{2 1 4 0 0}$ \\
May & 8900 \\
June & 6900 \\
July & $\mathbf{1 1 8 0 0}$ \\
August & $\mathbf{1 1 6 0 0}$ \\
September & 8900 \\
October & $\mathbf{9 6 0 0}$ \\
November & 8000 \\
December & 5300 \\
\hline
\end{tabular}




\subsection{Seasonality Causes}

As mentioned before, there are many factors causing seasonality in tourism demand of a tourism destination. These are natural and institutional factors. The natural factors causing seasonality are associated with the climate elements, and the resulted seasonality is often called "natural seasonality". For the institutional factors, they are mainly related to the legislations, leaves and holidays which lead to the so-called "the institutional seasonality" (Bigović, 2011). In addition, the social factors "(such as: social pressures, tastes and preferences, sporting seasons and traditions)" was considered as a third factor causes seasonality (Butler, 2001). Economic factors can also be considered as the fourth factor that contribute in the increase or decrease in tourism demand such as services' prices in different tourism seasons (Koenig \& Bischoff, 2005).

It is worth mentioning that Petra is a cultural heritage site attracting specific type of tourists. Therefore, Petra with one function is not preferable for other types of tourists such as nature-based tourism, community-based tourism, or adventure tourism. On the other hand, both natural and institutional factors are responsible about tourism seasonality in Petra. International visitors to Petra are concentrated in April due to Easter holiday (institutional cause), and nice weather and environment in Spring semester (natural cause). In the Jordanian context, Petra, in April, receives the largest quantum of Jordanian visitors during the year representing the peak season. Spring semester with a moderate and preferable temperature is the first and most important reason responsible about tourism seasonality in Petra. The second reason is the concentration of the recreational schools' journeys in Jordan in this month.

\subsection{Seasonality Effects}

The accommodation sector is the most affected sector by the variation of tourism demand in Petra. Occupancy rate of hotels is associated with and a direct result of the number of visitors to Petra. January, February, December, June, July, and August recorded the lowest occupancy rate of hotels in Petra ranging from $21 \%$ to $30 \%$ on average during the study period. This situation makes a loss of profits potential as well as administrative scheduling problems for accommodation properties in Petra. International tourists constitute the vast majority of visitors to Petra representing $81 \%$ of total visitors during the year. Therefore, any decline in the number of international visitors to Petra, will be reflected on the occupancy rate of hotels in the region. But the decline in the number of Jordanian visitors to Petra will not affect tremendously due to two reasons. The first cause is the slight proportion of Jordanian visitors to Petra (\%19). While the second reason is the fact that the economic impact of local visitors is too modest since most of Jordanians visit Petra during the day and return back without using facilities and accommodation services in the city. Tourism seasonality is considered a main challenge faces investment in the tourism sector especially the accommodation sector in Petra due to low feasibility.

\section{Conclusion and Future Research}

This study aimed to measure tourism seasonality in Petra between 2006-2017. Therefore, four methods were used to measure tourism seasonality in Petra. They all indicated the existence of seasonality in tourism demand in the study area. Of them, seasonality ratio, seasonality indicator and Gini coefficient had showed a modest level of tourism seasonality in Petra during 2006-2017. The results of the seasonality index give a clear picture of seasonality during the year. It displayed two peaks of tourism demand in Petra. The first and the highest one was in April and the second in the months of October and November. Seven months were below the average representing the low season of tourism demand in Petra. These are December, January and February as well as June, July, August and September. This was mainly due to the weather in these months which represent the coldest and warmest months in the year respectively. The results of this study agree with previous literature which indicated that the appropriate and simple way to calculate seasonality patterns at tourism destinations is seasonality index (Nadal et al., 2004; Koenig and Bischoff, 2005).

According to the study results, foreign visitors play a significant role in tourism seasonality in Petra concentrating in two peaks (April, October and November). In addition to April, Jordanian visitors concentrate in July and August creating a third peak season in summer, which in turn, decrease tourism seasonality in Petra. Thus, planners and decision makers have to focus on encouraging Jordanians to visit Petra outside these peak seasons through diversifying tourism activities catering the desire of different types of tourists during summer vacation. Moreover, Mega events such as international conferences should be oriented by the government to be held in Petra in low seasons.

Future research is recommended to be conducted in the same area. An evaluation of actual strategies adopted by hotels in Petra to mitigate seasonality effects on service providers is needed to judge its efficiency. Furthermore, comparing overnights stay between tourism destinations in the country would be an interesting work to be conducted. Cooperation instead of competition is another issue should be examined among tourism destination in 
the Golden Triangle (Aqaba, Wadi Rum, and Petra), as well as Dana Biosphere reserve and its effect on tackling seasonality in the region.

\section{Acknowledgments}

This research is a part of a project funded by Faculty of Research and Quality Assurance at The University of Jordan.

\section{References}

Aljamaliah, M. (2006). Tourism seasonality in Petra region (Unpublished master's thesis). The University of Jordan, Jordan.

Allcock, J. B. (1989). Seasonality. Seasonality, 387-392.

BarOn, R. (1975) Seasonality in tourism: A guide to the analysis of seasonality and trends for policy making. Economist Intelligence Unit, Technical Series No. 2, London.

Baum, T., \& Hagen, L. (1999). Responses to seasonality: The experiences of peripheral destinations. The International Journal of Tourism Research, 1(5), 299.

Bigović, M. (2011). Quantifying seasonality in tourism: A case study of Montenegro. Academica Turistica: Tourism \& Innovation Journal, 4(2), 15-32.

Butler, R. W. (1994). Seasonality in tourism: Issues and problems. In A. V. Seaton (Ed.), Tourism, the state of the art (pp. 332-339). Chichester: Wiley.

Butler, R. W. (2001). Seasonality in tourism: Issues and implications. Seasonality in tourism, 5-21.

Butler, R., \& Mao, B. (1997). Seasonality in Tourism: Problems and Measurement. In P. Murphy (ed.), Quality Management, Chichester, New York, Wiley.

Chan, F., \& Lim, C. (2011). Spectral Analysis of Seasonality in Tourism Demand. Mathematics and Computers in Simulation, 81, 1409-1418.

Chen, T., \& Pearce, P. L. (2012). Research note: Seasonality patterns in Asian tourism. Tourism Economics, 18(5), 1105-1115.

Chung, Y. J. (2009). Seasonality in tourism: A review. e-Review of Tourism Research, 7(5), 84-88.

Commons, J. and Page, S. (2001) 'Managing Seasonality in Peripheral Tourism Regions: The Case of Northland, New Zealand'. In T. Baum and S. Lundtrop (eds.), Seasonality in Tourism, New York, Pergamon, Amsterdam, pp.153-172.

Coshall, J., Charlesworth, R., \& Page, S. J. (2015). Seasonality of overseas tourism demand in Scotland: A Regional Analysis. Regional Studies, 49(10), 1603-1620.

Cuccia, T., \& Rizzo, I. (2011). Tourism Seasonality in Cultural Destinations: Empirical Evidence from Sicily. Tourism Management, 32, 589-595.

DERROUICHE, S., \& MEBIROUK, M. E. B. Seasonal concentration of the international tourism demand in Algeria: A measurement and decomposition by nationalities for the period (2000-2013).

Duro, J. A. (2016). Seasonality of hotel demand in the main Spanish provinces: Measurements and decomposition exercises. Tourism Management, 52, 52-63.

Fang, Y., \& Yin, J. (2015). National assessment of climate resources for tourism seasonality in China using the tourism climate index. Atmosphere, 6(2), 183-194.

Fernández-Morales, A., \& Mayorga-Toledano, M. C. (2008). Seasonal concentration of the hotel demand in Costa del Sol: A decomposition by nationalities. Tourism Management, 29(5), 940-949.

Fernández-Morales, A., Cisneros-Martínez, J. D., \& McCabe, S. (2016). Seasonal concentration of tourism demand: Decomposition analysis and marketing implications. Tourism Management, 56, 172-190.

Goh, C. (2012). Exploring impact of climate on tourism demand. Annals of Tourism Research, 39(4), 1859-1883.

Goulding, P.J., Baum, T.G. and Morrison, A.J. (2004). Seasonal Trading and Lifestyle Motivation: Experiences of Small Tourism Businesses in Scotland. Journal of Quality Assurance in Hospitality \& Tourism, 5(2/3/4), 209238.

Hylleberg, S. (1992). Modelling seasonality. Oxford University Press.

Jang, S. S. (2004). Mitigating Tourism Seasonality. Annals of Tourism Research, 31(4), 819-836. 
Karamustafa, K., \& Ulama, S. (2010). Measuring the seasonality in tourism with the comparison of different methods. EuroMed Journal of Business, 5(2), 191-214.

Koc, E., \& Altinay, G. (2007). An analysis of seasonality in monthly per person tourist spending in Turkish inbound tourism from a market segmentation perspective. Tourism Management, 28(1), 227-237.

Krakover, S. (2000). Partitioning seasonal employment in the hospitality industry. Tourism Management, 21(5), 461-471.

Kulendran, N., \& Dwyer, L. (2010). Seasonal variation versus climate variation for Australian Tourism. CRC for Sustainable Tourism Pty Limited.

Kulendran, N., \& Wong, K. K. (2005). Modeling seasonality in tourism forecasting. Journal of Travel Research, 44(2), 163-170.

Lee, C., Bergin-Seers, S., Galloway, G., \& McMurray, A. (2008). Seasonality in the tourism industry. Impacts and strategies. Gold Coast: CRC for Sustainable Tourism Pty Ltd.

Mustafa, M. H., \& Tayeh, S. N. A. (2011). The impacts of tourism development on the archaeological site of Petra and local communities in surrounding villages. Asian Social Science, 7(8), 88.

Nadal, J. R., Font, A. R., \& Rossello, A. S. (2004). The economic determinants of seasonal patterns. Annals of Tourism Research, 31(3), 697-711.

Pegg, S., Patterson, I., \& Gariddo, P. V. (2012). The impact of seasonality on tourism and hospitality operations in the alpine region of New South Wales, Australia. International Journal of Hospitality Management, 31(3), 659-666.

Rawashdeh, Akram. (2014). Measuring tourism seasonality in Jordan using Gini Coefficient. Mu'tah Journal for Research and Studies, 9(2), 243-266.

Ridderstaat, J., Oduber, M., Croes, R., Nijkamp, P., \& Martens, P. (2014). Impacts of seasonal patterns of climate on recurrent fluctuations in tourism demand: Evidence from Aruba. Tourism Management, 41, 245-256.

Rosselló, J., \& Sansó, A. (2017). Yearly, monthly and weekly seasonality of tourism demand: A decomposition analysis. Tourism Management, 60, 379-389.

Soboll, A., \& Dingeldey, A. (2012). The future impact of climate change on Alpine winter tourism: A highresolution simulation system in the German and Austrian Alps. Journal of Sustainable Tourism, 20(1), 101120.

Soesilo, J., \& Mings, R. (1986). Assessing the seasonality of tourism. Visions in Leisure and Business, 6(2), 2538.

Wall, G., \& Mathieson, A. (2006). Tourism: Change, impacts, and opportunities. Pearson Education.

Weidner, S. (2006). Seasonality in tourism: A review of seasonality of hotel accommodation in New Zealand.

WTTC, W. T. (2015). Travel \& Tourism Economic Impact 2015 Jordan. WTTC, World Travel and Tourism Council.

Zhang, H. Q., \& Kulendran, N. (2017). The impact of climate variables on seasonal variation in Hong Kong inbound tourism demand. Journal of Travel Research, 56(1), 94-107.

\section{Copyrights}

Copyright for this article is retained by the author(s), with first publication rights granted to the journal.

This is an open-access article distributed under the terms and conditions of the Creative Commons Attribution license (http://creativecommons.org/licenses/by/4.0/). 